\title{
Erratum to: High expression of the Ets-related gene (ERG) is an independent prognostic marker for relapse-free survival in patients with acute promyelocytic leukemia
}

\author{
Anna Hecht • Daniel Nowak • Verena Nowak • Benjamin Hanfstein • \\ Andreas Faldum • Thomas Büchner • Karsten Spiekermann • Cristina Sauerland • \\ Eva Lengfelder • Wolf-Karsten Hofmann • Florian Nolte
}

Published online: 9 May 2014

(C) Springer-Verlag Berlin Heidelberg 2014

\section{Erratum to: Ann Hematol (2013) 92:443-449 \\ DOI 10.1007/s00277-012-1648-2}

We have to report that in subsequent studies performed on the same patient cohort investigated for ERG expression in this article, we by chance found that in 7 out of 86 patients the PML/RARA-fusion transcript could not be detected. The reason for this discrepancy with the original diagnostic findings remains unclear. However, repeating our analyses on the remaining cohort of 79 securely PML/RARA-positive APL patients we could confirm our previously reported findings regarding ERG expression levels and prognosis: High expression of ERG ( $\geq 75$ th percentile) in APL patients is associated with an inferior relapse free survival (RFS: $43 \%$ vs $78 \%$ for $\mathrm{ERG}^{\text {low }}$ after 10 years of follow-up; $\mathrm{p}=0.004$ ) and an inferior relapse free interval (RFI: $74 \%$ vs. $97 \%$ after 10 years of follow-up; $p=0.003$ ). The overall survival of responders to induction therapy was $62 \%$ in the ERG ${ }^{\text {high }}$ group compared to $81 \%$ in the $\mathrm{ERG}^{\text {low }}$ group. However, as reported before, this difference did not yield statistical significance $(\mathrm{p}=0.11)$.

The online version of the original article can be found at doi:10.1007/ s00277-012-1648-2.

A. Hecht · D. Nowak · V. Nowak · B. Hanfstein · E. Lengfelder

W.-K. Hofmann $\cdot$ F. Nolte $(\square)$

Department of Hematology and Oncology,

University Hospital Mannheim,

Theodor-Kutzer-Ufer 1-3,

68167 Mannheim, Germany

e-mail: florian.nolte@medma.uni-heidelberg.de

A. Faldum $\cdot$ C. Sauerland

Institute of Biostatistics and Clinical Research,

University of Münster, Münster, Germany

T. Büchner

Department of Hematology/Oncology, University of Münster,

Münster, Germany

K. Spiekermann

Department of Hematology/Oncology, University of Munich,

Munich, Germany 